ConNotas. Revista de crítica y teoría literarias / Vol. V, Núm. 9 / 2007

\title{
Ciencia y fantasía en la narrativa de Amado Nervo
}

\author{
FrANCISCO ARAgÓN*
}

Resumen:

La coronación del positivismo como filosofía hegemónica durante el siglo XIX supuso la invalidación de un saber tradicional que se sustentaba en el imaginario, el mito, el espacio onírico y en sí en todas aquellas manifestaciones que no estaban condicionadas por ninguna clase de límites. Por lo tanto, en virtud del esquematismo y del afán clasificador de la nueva filosofía positivista, la experiencia humana padece un corte en su interior: las realidades factuales, tangibles, son separadas del reino de la imaginación. Es en esta coyuntura histórico-epistemológica que Amado Nervo (1870-1919), junto a otros representantes del modernismo hispanoamericano, concibe una obra artística en la que, precisamente debido a las circunstancias ya señaladas, podemos constatar una necesidad de suturar la incisión y recuperar la unidad perdida. Así, en sus cuentos fantásticos, Nervo muestra con frecuencia tal intención al conjuntar las herramientas de la indagación científica con la libertad del saber de la imaginación.

Palabras clave:

Fantástico, positivismo, modernistas, cientificismo, ocultismo, imaginación.

* Universidad Nacional Autónoma de México. 
El presente trabajo no constituye sino la primera fase de una investigación de mayor aliento, la cual busca establecer todos los posibles contactos entre el autor nayarita y el universo de la ciencia. En esta ocasión me propongo simplemente trazar algunas de las líneas de investigación al respecto, analizar algunos testimonios que el autor dejó como evidencia de su particular acercamiento a la ciencia, así como adelantar hipótesis sobre la manera en la cual ese pensamiento pasó a formar parte de las obras de ficción fantástica del autor.

\section{Religión científica del porvenir}

$\mathrm{Al}$ igual que autores muy reconocidos en el ámbito rioplatense como Leopoldo Lugones, Eduardo Ladislao Holmberg y Horacio Quiroga, Amado Nervo vivió las tensiones propias del fin del siglo XIX. Su generación, educada bajo la insignia positivista, la fe en el progreso, la confianza en la razón como manera de conocer y comprender el mundo, se enfrentó también con la decepción por los productos ambivalentes del avance tecnológico. El materialismo cientificista fracasó en su afán de reducir a causas naturales (verificables), como la conservación de la materia o las leyes de la termodinámica, fenómenos psíquicos y espirituales, por lo que la promesa hecha al sustituir el paradigma religioso quedaba incumplida, desamparando así toda la dimensión espiritual del ser humano. Cuerpo y mente, materia y espíritu parecían en ese momento más irreconciliables que nunca.

Por ello, la cruzada ideológica para los intelectuales modernistas fue la de reconquistar la unidad perdida, recuperar la espiritualidad, el misticismo que sus almas necesitaban, pero sin dejar de ser (esto era muy importante) hombres de su tiempo; la simple vuelta al cristianismo no era alternativa, pero renunciar al misterio que los apasionaba tampoco. Nervo encontró la respuesta a esta paradoja en la ciencia, aunque esta afirmación tendría que ser matizada.

Se sabe que Nervo fue miembro de la Asociación Mexicana de Astronomía, actividad de la cual se conservan, además de instru- 
mentos ópticos en el museo casa de Tepic, dos conferencias con el tema de la luna. En la primera de ellas, titulada "La literatura lunar y la habitabilidad de los satélites", Nervo se ubica dentro de tal disciplina: "Ante todo una confesión: Yo no soy astrónomo, ni pretendo serlo. No estoy preparado para esa ciencia, la más bella de todas, más que por el amor inmenso que le tengo desde niño. Soy un aficionado a la Cosmografía..." (Obras II, 496); estas palabras describen también el resto de su labor científica directa, pues a diferencia de Ladislao Holmberg, biólogo, matemático y naturalista, Nervo pudo dedicar poco tiempo de su atareada vida a la investigación.

El contacto principal de Nervo con la ciencia fue, pues, fundamentalmente a través de sus lecturas. Además de la astronomía, sus intereses abarcaron la biología, la medicina y, principalmente, la psicología, sobre todo en lo relativo a fenómenos que empezaban a investigarse en la época, por ejemplo la doble percepción (como una explicación del sentimiento de deja vî), el supuesto origen inconsciente del genio en los artistas, la doble personalidad, el sueño, etcétera. A partir de estas lecturas se define el que sería el papel principal de Amado Nervo en relación con la ciencia, y es el de esmerado divulgador, papel que el autor tomaba muy en serio pues lo consideraba casi como un apostolado:

La divulgación de los conocimientos hecha con amor es omnipotente [...] Los mexicanos no acertamos quizá a inventar aún grandes cosas pero sí podemos divulgar muchas [...] Nuestra enseñanza deberá ser límpida y cristalina y las luces que difundamos habrán de temblar en ella como los remotos luceros en la fuente. (Obras I, 1346)

A esta labor de divulgación dedica versos, cuentos, crónicas y ensayos. En sus ensayos, el acercamiento a la ciencia no es empirista, no describe experimentos, ni cita estadísticas, sino que está más interesado en la reflexión, en la filosofía de la ciencia, por decirlo de este modo. Expone ideas surgidas de sus lecturas, principalmente de empiristas de lengua inglesa como William James y Bergson, 
así como científicos de altos vuelos, como el célebre químico y físico Sir William Crookes, interesados también, y ésta es la conexión directa con los intereses profundos de Nervo, en los fenómenos psíquicos. Junto a estos filósofos y científicos, y sin ninguna distinción de grado, Nervo refiere la opinión de teósofos como C. W. Leadbeater, e incluso la de espiritistas como Allan Kardec o Leyson, que sólo tienen en común con los primeramente mencionados esa nueva necesidad de relativizar la separación tajante que el paradigma positivista instauró entre materia y espíritu.

La postura que Nervo adopta ante los avances de la tecnología y su particular visión de los alcances éticos de la ciencia van desde la euforia hasta la disforia, empleando los términos que el crítico Rodolfo Mata utiliza en el caso similar de José Juan Tablada (119). En el breve ensayo "Los sabios y el misterio de la vida", Nervo reflexiona sobre el papel que los últimos descubrimientos (entre ellos el aeroplano, la transmutación de la materia, la telegrafía, etc.) jugarán en el desarrollo de la humanidad. Para él, el acceso a una sociedad utópica vendrá inequívocamente de la mano de la ciencia:

La conquista de la energía intra-atómica, “de esa energía inmensa, capaz de dislocar y romper el equilibrio indestructible que existe en los electrones constitutivos del átomo" y merced a la cual se redimiría al mundo, desapareciendo las desigualdades de la suerte que obligan a las cinco sextas partes de la humanidad a trabajar sin descanso para producir lo necesario a una sexta parte privilegiada. La energía intra-atómica, la utilización de las mareas y el aprovechamiento del calor solar podrían por sí solo realizar con exceso toda la suma de trabajo que el mundo necesita para vivir. (Obras II, 753)

Contrario a este optimismo que ahora nos parece necesariamente ingenuo, Nervo con frecuencia añade una objeción relativa a que, si bien la ciencia ha descrito el macro y el microcosmos, es incapaz de comprender el principio creador, la voluntad que anima todas las relaciones de la materia: "Pero el misterio de lo que esté más allá de esos horizontes será tan esquivo, tan ilimitado, tan im- 
ponente como siempre..." (Obras II). Nuevamente el materialismo fracasa ante la barrera del misterio.

Un poema del libro Serenidad también trata el mismo problema:

Células, protozoarios, microbios... Más allá de vosotros, ¿hay algo?

Pronto nos lo dirá

el microscopio, intruso, pertinaz y paciente.

Mas tal vez la materia se empequeñecerá

tanto bajo su lente,

que un día, como espectro, se desvanecerá

ante el ojo del sabio, quedando solamente

la Fuerza creadora, cuyo oleaje va

y viene omnipotente

y fuera de la cual nada es ni será. (Obras II, 1583)

En este caso sí se produce una suerte de síntesis; la nueva forma de pensamiento moderno no excluye una visión trascendente de la vida y el universo. En el ensayo "La muerte del ateísmo", el autor comienza señalando, de acuerdo con Jean Finot, que el ateísmo "de nuestros días" no es más que una palabra vacía: "un hombre culto no puede ya proclamarse ateo (conforme a la antigua definición). No puede ya negar la influencia de fuerzas que escapan a su cerebro y de principios que ignora" (Obras II, 777). Ésta no es simplemente una crítica al racionalismo, sino la opción integrista que muchos pensadores de ese fin de siglo encontraron como respuesta a la tensión de la cual hemos venido hablando. Más adelante, en el mismo ensayo, el autor apunta:

Finot piensa que los espiritualistas y los materialistas acabarán por llegar a la conciliación en el terreno científico. Yo lo creo también firmemente.

En realidad, todos los grandes filósofos modernos -Bergson entre ellos- esperan de la ciencia la fórmula religiosa del porvenir. (Obras II, 778) 
Para Nervo, esta nueva mentalidad vendrá como parte de la inevitable evolución de la especie humana, que sabrá ver unidad en lo que la ilusión del materialismo vio ruptura: "Quién sabe si el siglo actual -añado yo- verá el alborear de una religión universal, eminentemente científica" (Obras II, 779). Poco se oculta para el conocedor de Nervo, o del siglo XIX en general, que esa religión hipotética, a la que el mundo supuestamente aspira, tiene su modelo en la teosofía, doctrina filosófica, religiosa y científica al mismo tiempo, de la cual Nervo ya era adepto.

\section{Fantaciencia}

La ciencia para Nervo, pues, se encuentra relacionada indisolublemente con su religiosidad. Nervo es científico en su espiritualidad y espiritual en la ciencia. Esta característica no es un fenómeno aislado sino muy común entre los modernistas latinoamericanos que gustaron del género fantástico y, en general, es un síntoma de la sociedad occidental producto de una coyuntura específica propia del fin del siglo XIX.

En un nivel muy esquemático, podría decirse que los escritores modernistas emplearon la ciencia en sus cuentos fantásticos con los siguientes propósitos:

a) Dar verosimilitud a sus ficciones: es decir, si se va a presentar alguna transgresión a las leyes de la naturaleza, pretendiendo que este suceso sea creíble, es necesario rodearlo de un discurso, como el científico, que goce de una gran credibilidad.

b) Señalar la ineficacia de la ciencia en terrenos espirituales: no importa qué tan avanzados sean, los conocimientos científicos nunca desvelarán los misterios esenciales de la existencia.

c) Distanciarse de un compromiso con el misticismo: el escritor, que muchas veces se siente sinceramente atraído por las explicaciones sobrenaturales o religiosas, prefiere en sus narraciones una explicación lógica, científica o pseudocien-tífica de los hechos. 
Los diversos sistemas ocultistas en boga, así como los textos de divulgación científica, brindaron un arsenal completo de temas y motivos a los cuentistas, como la transmigración de las almas, la comunicación con los muertos, el magnetismo, el viaje en el tiempo y la cuarta dimensión, etc. El autor, convencido a medias, a medias escéptico, dejaba volar su imaginación seguro de no parecer supersticioso ni folclórico.

En sus obras de ficción fantástica (cuento, cuento largo e híbridos de crónica-ensayo), Nervo emplea estas nuevas posibilidades en la confección de dos tipos de relatos principalmente:

a) Relato tecnologista, el cual desarrolla una historia a partir de un discurso pseudocientífico o un pseudo adelanto tecnológico.

b) Relato evolucionista, en el cual crea historias de anticipación empleando teorías reales en boga como, por ejemplo, la evolución de las especies.

En ambos tipos de relato el ser humano se ve como sujeto de un devenir al que está predestinado naturalmente; en el relato tecnologista la mano del hombre interviene para acelerar de algún modo dicho proceso; en el relato evolucionista sólo se busca ser espectador de ese proceso natural que modifica la vida de la tierra a lo largo del tiempo.

El modelo del relato tecnologista es simple y Nervo lo deduce del escritor H. G. Wells: "Me refiero a Los primeros hombres en la luna del joven y ya celebérrimo escritor inglés Herbert George Wells, autor de las obras en que sobre una base perfectamente científica campea una de las imaginaciones más privilegiadas del planeta" (Obras II, 497).

La mayoría de las veces el argumento lógico o "científico" no es lo suficientemente sólido para soportar la imaginería de la historia; en estos casos, la técnica de Nervo, como la de otros autores (incluyendo al propio Wells), es evitar los detalles técnicos o científicos descriptivos, alegando ignorancia o consideración a la ignorancia, o al tiempo, o a la paciencia del lector implícito. Por ejemplo, en la novela breve de Nervo El sexto sentido, el protagonista, que es 
también el narrador, acaba de sufrir una operación mediante la cual ahora es capaz de ver el futuro con la misma naturalidad con la que se ve lo que ocurre en el presente; a pesar de que se trata de un procedimiento quirúrgico trascendental, el narrador nos niega cualquier detalle o explicación. En otro caso, el del cuento "El hombre al que le dolía el pensamiento", el autor simplifica exageradamente la descripción de un novedoso padecimiento y trata de confundir al lector:

Mis menguados conocimientos me impedirían describiros técnicamente esta enfermedad; mi patología es harto rudimentaria. Pero, en fin, suponed que hay en el cerebro de este hombre una irritabilidad extraña, y que merced a ella, cada célula sufre al "elaborar" el pensamiento. Digo "elaborar" no porque sea yo materialista precisamente, sino porque no encuentro un verbo más adecuado. El cerebro, para mí, es un instrumento de aquello misterioso y casi divino que hay en nosotros; pero aquí, en el caso que analizamos, ese instrumento adolece de una hiperestesia tal, que cada pensamiento al producirse, "pincha" como un alfilerazo. (Obras II, 599)

El relato tecnologista comparte territorios con el género de divulgación científica; son similares en cuanto éste simplifica el conocimiento para hacerlo comprensible al mayor número de personas. El tono de divulgación científica debió ser, pues, el que el autor de este tipo de ficciones buscó mimetizar; así, por ejemplo, una noticia titulada "Los ciegos pueden ver", aparecida en el diario capitalino El mundo el sábado 14 de octubre de 1899, declaraba con toda la seriedad de una noticia que

El Dr. Pedro Stiens, notable sabio ruso residente en Londres, ha informado a algunos representantes de la prensa inglesa que los estudios experimentales a que por mucho tiempo se ha venido dedicando, han fructificado, hallándose hoy en aptitud de poder asegurar que ha inventado un procedimiento mediante el cual el "milagro" de hacer ver, aun a los ciegos de 
nacimiento es ejecutado fácilmente. El invento del Dr. Stiens no consiste, como pudiera creerse en la restauración del poder óptico al ojo humano [...] El aparato maravilloso está destinado a sustituir a los lentes que así como estos aumentan la visión de los cortos de vista, hará, por medio de la electricidad, que tan pronto como esté en contacto con el cuerpo del individuo éste vea con tanta claridad como el que posea los ojos en perfecto estado.

Las similitudes entre ambos discursos, uno pretendidamente real y otro ficticio, son elocuentes por sí mismas.

Para la mayoría de las personas de finales del siglo XIX, los verdaderos límites de las posibilidades de la ciencia no estaban del todo claros; el beneficio de la duda se otorgaba, podemos suponer, con facilidad, circunstancia que aprovecharon sin duda tanto extorsionadores como escritores deseosos de revestir los vuelos de su imaginación con esa base institucional (racional) de credibilidad.

Algunas de las narraciones de Nervo que emplean esta técnica son, por ejemplo, "El descubrimiento del doctor Carrel", especie de crónica en la cual la técnica de los trasplantes recientemente descubierta podría avanzar tanto en un futuro no tan lejano que se volvería algo ridículamente común, y "Los muertos", texto en el que un dispositivo tecnológico hace posible la comunicación directa, sin sesiones espiritistas, con los difuntos.

El segundo tipo de relato, el evolucionista, tuvo como modelo la obra de Camille Flammarión, astrónomo y divulgador a quien Nervo dijo haber tenido la oportunidad de conocer en persona en 1906. Flammarión reconoció la importancia de la ciencia especulativa que predice escenarios futuros basándose en los datos actuales y ya conocidos, deduciendo consecuencias futuras de causas presentes; fue además antologador y sistematizador de la literatura de utopías.

En los relatos evolucionistas de Nervo, la humanidad se transforma tanto fisiológica como socialmente, ya sea que la historia esté situada en el futuro lejano ("La última guerra") o próximo, o se asista a contemplar la evolución de los seres en otros mundos ("La 
literatura lunar"), o se recreen las consecuencias en la humanidad de cataclismos geológicos ("La última diosa") o ambientales ("Las nubes"). Los géneros literarios vinculados con este tipo de relatos son la literatura de utopía y la ciencia ficción; géneros que no procuran una ruptura o enfrentamiento con las leyes de la realidad, como sí sucede en el género fantástico, sino que observan esas mismas leyes pero llevándolas hasta sus últimas consecuencias.

De este modo, se puede sugerir la existencia de otras posibilidades de la realidad sin la necesidad de recurrir a la parafernalia de los cuentos de hadas; se puede ser hombre del siglo XX y, a pesar de la aparente paradoja, racional en lo fantástico.

En Amado Nervo se combinan la atracción por el aspecto metafísico de la realidad con la confianza en que la ciencia, una vez despojada de sus prejuicios materialistas, será el instrumento absoluto de conocimiento humano; en sus ficciones narrativas, Nervo descree por completo de simplemente representar el folclore siniestro o las supersticiones populares; para él si la imaginación va a rasgar los pretenciosos velos del realismo literario, lo hará también con un método científico, sólo así, y esa es su interpretación muy personal de la obra de Wells, el relato imaginativo (fantástico) podrá seguir hablándole a las generaciones futuras.

\section{Bibliografía}

“Los ciegos pueden ver." El mundo. 14 octubre de 1899.

Mata, Rodolfo. Las vanguardias literarias latinoamericanas y la ciencia.

Tablada, Borges, Vallejo y Andrade. México: FCE, 2003.

Nervo, Amado. Obras completas I. $4^{\text {a }}$ ed. Madrid: Aguilar, 1973.

Obras completas II. Madrid: Aguilar, 1952. 